\title{
The Implementation of Multimedia Learning Materials in Teaching English Speaking Skills
}

\author{
Andi Tenri Ampa (Corresponding author) \\ Department of English Education, Faculty of Teachers Training and Education \\ Unismuh, Makassar, South Sulawesi, Indonesia
}

Tel: 628-525-500-4490_E-mail: atenri59@yahoo.com

\begin{abstract}
Muhammad Amin Rasyid
Department of English Education, Faculty of Teachers Training and Education

State University of Makassar, South Sulawesi, Indonesia

E-mail: muhammadaminrasyid_unm@yahoo.com
\end{abstract}

\section{Asfah Rahman}

Department of English Education, Faculty of Teachers Training and Education

State University of Makassar, South Sulawesi, Indonesia

\section{Haryanto}

Department of English Education, Faculty of Teachers Training and Education

State University of Makassar, South Sulawesi, Indonesia

E-mail: aharyanto_fbsunm@yahoo.co.id

Muhammad Basri D.

Department of English, Faculty of Letters, UMI Makassar, South Sulawesi, Indonesia E-mail: basri_fs@yahoo.com

Received: August 2, 2013 Accepted: August 19, 2013 Published: August 20, 2013

doi:10.5296/ijele.v1i3.4153 URL: http://dx.doi.org/10.5296/ijele.v1i3.4153 
Abstract

This study aimed to implement the multimedia learning materials in teaching speaking skills. The problems investigated were to what extent the practicality of the multimedia learning materials was. This was gathered from the lecturers' and the students' responses. Similarly, it also investigated the effectiveness of the multimedia learning materials for teaching speaking skills. Three lecturers had implemented the multimedia learning materials, and the results of the implementation were significantly effective. It was indicated by the comparison between t-test $>$ t-table for groups I, II, III (7.424>2.093; 7.796>2.093; 10.342>2.093).

It was concluded that the use of multimedia learning materials in teaching speaking skills was practical and effective.

Keywords: Multimedia, learning materials, praticality, effectiveness 


\section{Introduction}

The innovation of learning paradigm and the movements are caused by the rapid progress of technology. Therefore, the needs towards the multimedia learning materials really exist, due to the condition of technology which is much more developing. In the field of education in Indonesia, for examples, the students from Elementary School, Junior High School, Senior High School, are encouraged to know technology earlier. This need is legalized through the establishment of curriculum which includes the subject of computer in school of Indonesia. Even, to support the understanding of technology in schools, the government gradually assists schools by giving sets of computer hardware as a device of practice. Thus, it is obvious that the needs for learning materials based on technology as a device help the students learn English at the university.

With reference to the importance of the multimedia learning materials, the lecturers are expected to implement the multimedia materials for the improvement of learning; thus, it has become the urgent needs for the improvement of capabilities by the doers of education, especially for the lecturers to have capabilities and interest in designing the multimedia learning materials for each subject.

Cunningsworth (1995) also states that learning materials are a key component of teaching and learning process. They are used to help transfer information and skills to others. In general, there are two kinds of learning materials, i.e. printed materials and non-printed materials. The printed materials include textbook, module or course-book, handout, while the non-printed materials are such as cassettes or audio materials, videos, or computer-based materials. Printed material is a material using papers, which can serve for learning purposes or submission of information. From the point of educational view, the various learning materials are categorized as parts of learning media (Kemp dan Dayton, 1985). As part of the learning media, printed materials have a significant contribution in the learning process. However, they still have the weakness which is not able to present the movement. Therefore, the printed materials should be completed with the multimedia materials.

Multimedia materials are categorized as non-printed materials. Richard (2000) states that multimedia learning materials are the use of computer to present and combine text, graphic, audio, video, and animation with links and tools that let the users interact, create, and communicate. Thus, in teaching and learning process, there must be a computer to coordinate what the users see and hear, and interact with users; there must be links that connect information; there must be navigational tools that let users connect information; and there must be ways for users to gather, process, and communicate their own information and ideas.

\section{Research Questions}

The research questions are 1) To what extent is the practicality of the multimedia learning materials for speaking skills? and 2) How effective are the multimedia learning materials used in teaching speaking skills? 


\section{Literaure Review}

\subsection{Multimedia in Education}

Mayer (2001) defines multimedia as the combination of various digital media types, such as text, images, sound, and video, into an integrated multi-sensory interactive application or presentation to convey a message or information to an audience. He also describes potential benefits of multimedia that humans possess visual and auditory information processing capabilities. Multimedia takes advantage of both capabilities at once. In addition, these two channels process information quite differently, so the combination of multiple media is useful in calling on the capabilities of both systems. Meaningful connections between text and graphics potentially allow for deeper understanding and better mental models than from either alone.

The same idea expressed by Kanwar (2007) that MMLM refers to computer-based learning material which is made available to an individual or a group either on-line or off-line and involves an integration of two or more digital media such as text, images, sound, video, animation, to promote interesting learning process. When learning with multimedia the brain must simultaneously encode two different types of information, an auditory stimulus and a visual stimulus. Baddeley and Hitch (1974) in (Kanwar, 2007) propose a theory of working memory which has two largely independent subcomponents that tend to work in parallel one visual and one verbal/acoustic. This allows us to simultaneously process information coming from our eyes and ears.

Ivers and Baron (2010) state that multimedia allows to convey the understanding of a topic in a variety of ways, provides the students with opportunity to explain their ideas to others. It also provides the students with a communication and offers them new insight into organizing, and evaluating information. Besides, multimedia has the potential to change the roles of teacher and students and interaction between them by allowing the students to create their own interpretation of information.

Previous researches have been conducted by some experts. Mayer (2001) reports that multimedia learning combining animation with narration generally improves performance on retention text better than when information is presented as either text or narration alone. More importantly, meaningful learning is demonstrated when the learner can apply what is presented in new situations, and students perform better on problem-solving when they learn. Similarly, Neo (2010) has conducted a research of multimedia learning and the results of the study show that by setting an authentic task, via a multimedia project, into a constructivist learning environment, students became highly motivated learners and active in their learning process and provided strong support and encouragement for educators to incorporate multimedia technology and constructivist learning into their classrooms.

\subsection{Guidelines for Preparing the Multimedia Learning Materials}

The use of multimedia may encourage students to work in groups, express their knowledge in multiple ways, solve the problem, revise their own work, and construct knowledge. Liu (2003) in Ivers and Baron, (2010: 3) notes the use of multimedia can address cognitive skills grouped 
into the categories, such as 'focusing, information gathering, remembering, organizing, analyzing, generating, and evaluating'. Multimedia allows the students to focus on course content, promote active and cooperative learning, engage students in higher-order thinking skills, represent ideas through a variety of media.

Furthermore, Ivers and Baron, (2010: 112) describes the main elements which make up a typical multimedia program, those are as follows:

\subsubsection{Text}

This is the base to most applications the on-screen display of words. The use of different styles, fonts and colours can be used to emphasize specific points. They should be easy to read. Besides, the text should be written grammatically.

\subsubsection{Image}

Seeing a picture of an object has more impact than merely reading about it. Examples include conventional artwork, computer-generated artwork, photographs or captured video frames.

\subsubsection{Video}

It can help make learning more meaningful to students. Integrating video production into classroom activities has many benefits for students. It may encourage collaboration and requires students to be active and constructive. Video can help make learning more meaningful.

\subsubsection{Animation}

Animations are graphic that imitate movement. All animations consist of a series of images that are shown in rapid succession and fool the eye into seeing motion.

\subsubsection{Sound}

Sound can be used in strategic parts of the program or during a movie to emphasize certain points. This may include speech, audio effects, sound and music.

\subsubsection{Interactivity}

This refers to the action that occurs as two or more objects have an effect upon one another.

\subsubsection{User Control}

There has to be some degree of user control so as to provide students with the option to leave certain parts of the application. On-screen options should exist for them to visit other areas of the program.

Besides the criteria above, the contents of multimedia materials should be very interesting and engage the students in learning. The design should display particular skill relevant with the 
students. The language should be appropriate, understandable, and very accurate. Therefore, the users are able to use the content with minimal training (user-friendly).

Furthermore, the other view states that there are some points that shoud be considered in order that the multimedia design is attractive to use in teaching and learning process. The design of multimedia that should be paid attention is related to Colors, text, Graphics, Navigation, Video, and Audio. The requirements related to the points are the 'background colors should be consistent; dark backgrounds use lighter text; for light backgrounds dark text should be used; long lines of text should be avoided; get straight to the point; do not place any text on top of a graphic unless the graphic is intended to hold text; use large enough font sizes, clearly visible fonts; do not have unrelated pictures present; graphs and charts should be labeled with text boxes or labels; make the icons big enough for the intended audience to see; include back up buttons, as well as forward ones and an exit button on each screen; the video clip should be very large, and should include a replay button; the audio uses a conversation style talking, and it doesn't have the conflict with the text that is on the screen. (Sun Associates, 2002).

All views above are the basis for preparing the multimedia learning materials for speaking skills. Previous research of multimedia has been conducted by Norhayati \& Siew (2004). They design story telling module and enjoyable reading module. The The principle objective of this project is to create a pedagogical tool that combines on-screen text, graphics, animation, audio and video in an enticing environment and thus enables the positive values and images of stories to be projected. Furthermore, Reeves, et.al. (2005) report the impact of computing and other technologies in higher education, examines the social relevance of that research, and recommends design research as a particularly appropriate approach to socially responsible inquiry. A description of the characteristics of design research is given, together with an argument for the more widespread adoption of this approach to enhance the quality and usefulness of research in computers and other technologies in education. They found that the interactive multimedia CD-ROM was a more effective instructional treatment than a traditional lecture.

\section{The Teaching of Speaking}

The priority in learning English is the mastery of speaking skills. The students think that they are succesful in learning English when they have improved their spoken language proficiency. According to Richard (1990) that there are three functions of speaking skills, namely interaction, transaction, and performance functions. 'Interaction function' refers to what we normally mean by conversation and describe interaction which serves a primary social function, such as 'greeting' when people meet because they wish to be friendly and establish a comfortable zone of interaction with others. 'Transaction' function refers to situation where the focus is what is said or done or transactions which focus on obtaining goods or services. Furthermore, performance function refers to public talk, that is, talk which transmits information to audiences, such as morning talks, public announcement, and speeches (John, 1996 in Richard, 1990).

Kellem (2009) proposes seven principles to consider when doing fluency building activities, 
those are: 1) Incorporate repetition 2) Increase speaking time 3) Prepare before speaking 4) Use familiar and motivating topics 5) Ensure appropriate level 6) Impose time limits 7) Teach formulaic sequences.

In this study the teaching of speaking skills is concerned with the the aspects and the principle mention above including the components of the speaking skills, namely pronunciation, vocabulary and structure.

\section{Method}

In this study, 60 students from three classes of English Department of Unismuh Makassar were taken as the participants. They were taught English speaking skills using multimedia: video, audio, text, picture, animation, and interactivity.

The way to implement the multimedia learning materials was that the lecturer explained the topic to be discussed and asked the students to watch the example of the dialogue and monologue through video. In the exercises of pronunciation, vocabulary, and structure, the students repeated the words and the sentences and then the students practiced doing conversation in pairs. For the last section, the students did monologue by retelling their ideas related to the topics and made another dialogue and monologue to be presented in front of the class.

This study used one group pretest-posttest design for three times. 20 students from class A, B, and $\mathrm{C}$ were given pretest and after that the treatments were also given to the three groups.

The instruments used were test and questionnaire. Test included pretest and posttest which aimed to findi the achievement of students' speaking skills before and after treatment. The results of pretest and posttest from each group were compared to know whether or not the multimedia learning materials are effective to implement in teaching speaking skills.

Besides, the questionnaire was used to gather the lecturers' and the students' responses about the implementation of the multimedia learning materials.

Data from the results of speaking test were analyzed quantitatively by using rating scores (6, $5,4,3,2,1)$ for 'accuracy' of pronunciation given by Heaton, (1989). The 'accuracy' of vocabulary and structure was scored by using the rubrics given by Omaggio (1986). The accuracy of 'content' was taken from California State University (2003), Long Beach Analytical Rubric. (http://www.csulb.edu/divisions/ aa/personnel/fcpd/resources/ge/).

Furthermore, the results of the data analysis were interpreted qualitatively. The rating scores were converted as follows:
5.1-6.0 ---(85\%-100\%) Very effective
2.1-3.0 ---(35\%-51\%) Ineffective
4.1-5.0 ---(68\%-84\%) Effective
$<2.0---(<34 \%) \quad$ Very ineffective
$3.1-4.0---(52 \%-67 \%) \quad$ Quite effective

Data analysis of the questionnaire Likert Scale $(5,4,3,2,1)$ by classifying that $4.1-5.0$ $(81 \%-100 \%)$ was very good, 3.1- $4.0(61 \%-80 \%)$ was good, $2.1-3.0(41 \%-60 \%)$ was quite good, 1.1- $2.0(21 \%-40 \%)$ was low, and $<1(<20 \%)$ was very low. 


\section{Results}

\subsection{The Practicality of the MMLM}

The practicality of the MMLM deals with the usability the MMLM for speaking skills in terms of the clarity, the facility and the appeal from the students as the target users and the appropriateness of content, language, presentation and graphic of the MMLM for speaking skills responded by the lecturers. The usability of the MMLM is obtained from the results of implementation to the university students. The results are related to the students' perception towards the materials used in teaching speaking skills. The percentage of achievement can be seen in the following table.

Table 1. The Students' Responses of the MMLM

\begin{tabular}{|l|l|l|}
\hline MMLM & Average & Per cent \\
\hline Appeal & 4.35 & 87.00 \\
Clarity & 4.10 & 82.00 \\
Facility & 4.65 & 93.00 \\
\hline & 4.37 & 87.33 \\
\hline
\end{tabular}

Data in Table 2 indicate that the appeal, the clarity and the facility of the MMLM are very high. However, the facility of MMLM is greater than the others $(93.00 \%)$, while the clarity of the MMLM is fewer the others (82\%). The appeal of the MMLM achieves $87 \%$. The researcher concludes that the students' responses to the MMLM are very good, so that they are suitable to use in teaching speaking skills.

Similarly, Nieveen (1999) in Plomp \& Nieveen (2010) state that one of the criteria for high quality interventions or products is practicality. It is related to the end-users, i.e. for instance the lecturers and the students. They should consider the products to be usable and that they are easy for them to use the materials. If these conditions are met, the products are practical. In connection with this, the students have very good responses towards the products, especially for the facility, the appeal, and the clarity of the products. Therefore, the practicality of the MMLM is very good.

Besides, the lecturers' responses towards the use of the MMLM in teaching speaking skills are also obtained through the results of implementation. There are four components proposed to be answered by the lecturers toward the appropriateness of the MMLM, namely the appropriateness of content, language, presentation and graphic. The results are shown in the following table. 
Table 2. Lecturers' Responses towards the MMLM

\begin{tabular}{|l|l|l|}
\hline Components & Average & Per cent \\
\hline Appropriateness of Content & 4.80 & 95.20 \\
Appropriateness of Language & 4.70 & 93.33 \\
Appropriateness of Presentation & 4.70 & 89.33 \\
Appropriateness of Graphic & 4.42 & 88.40 \\
\hline & 4.65 & 91.57 \\
\hline
\end{tabular}

Data in Table 2 indicate that the appropriateness of all components of the MMLM are very good based on the lecturers' responses. The lecturers' responses are concerned with the criteria as follows:

\subsubsection{Appropriateness of Content}

a. The contents of MMLM meet with the syllabus of speaking subject.

b. The materials meet with the students' needs and their levels.

c. The material substances are accurate, either in the printed materials or in the multimedia materials.

d. The materials can improve the students' insight of knowledge, because there are many interesting topics included in the MMLM.

e. The materials are very contextual and based on the students' daily lives.

So, the contents of the MMLM should include the suitability with the syllabus, the students' needs, the accuracy of material substances, the improvement of students' knowledge, and the contextual materials.

\subsubsection{Appropriateness of Language}

a. The spellings of the words should be correct.

b. The contents of the MMLM meet with the English grammatical rules.

c. The language use is effective. It means that the choices of words, the structure, the spellings of words, and the usage of punctuation are correct. The relationship among others are logical.

\subsubsection{Appropriateness of Presentation}

a. The learning objectives are very clear and meet with the presentation of the printed and multimedia materials. 
b. The sequences of presentation are logical. They are started from presentation, practice and production.

c. There is interaction between the speaker (narrator) and the students. The narrator says 'listen and repeat the words, phrases or sentences', and then the students repeat them. There is also interaction among the students.

So, the presentation of the MMLM which cover the suitablity of the learning objectives and the presentation of the printed and multimedia materials, the logical sequences of presentation, and the interaction between the speaker (narrator) and the students are considered very good according to the lecturers responses.

\subsubsection{Appropriateness of Graphic}

a. The font of the letters and its size in printed material are commonly used in the scientific writing, i.e. 'Arial 11'. In multimedia materials, the colour indicates the emphasized words.

b. The layout of the MMLM is clear. The points are placed appropriately.

c. Illustration refers to music illustration and picture illustration that are interesting for the students to learn.

d. Videos meet with the students and they are contextual. Narration is very natural because it is from the native language voices. The images are related to the topics.

The graphic of MMLM which includes font and size of the letters in printed materials, the layout, the illustration, and the presentation of contextual materials are considered also very good according to the leaturers' responses.

Mafumiko (2006) in Plomp \& Nieveen (2010) states that the evaluation needed to demonstrate the expected practicality of the prototypes is to try out to the lecturers and the students. Therefore, in tryout of the MMLM, the lecturers as the target users give feedback to the use of the materials, especially for the appropriateness of content, language, presentation, and graphic.

\section{The Effectiveness of MMLM}

The MMLM are able to consider as effective if the results achieved match with those needed or desired (Jacobs, et al, 2000). It is expected that the results of pretest and postest are significantly different. Therefore, the classification of scores is based on the rubric of speaking skills $(6,5,4,3,2,1)$ which cover the accuracy of content, pronunciation, vocabulary, and the English structure. The results of evaluation are shown in the following table.

Table 3. Results of Implementation

\begin{tabular}{|l|l|l|l|l|}
\hline Group & Mean score & $t$-observed & $\mathrm{df}$ & $t$-table \\
\hline Group 1 & & & & \\
\hline
\end{tabular}




\begin{tabular}{|c|l|l|l|l|}
\hline $\begin{array}{c}\text { Pretest } \\
\text { Postest }\end{array}$ & 64 & 7.424 & 19 & 2.093 \\
\hline $\begin{array}{c}\text { Group 2 } \\
\text { Pretest } \\
\text { Postest }\end{array}$ & 68 & 7.796 & 19 & 2.093 \\
\hline $\begin{array}{c}\text { Group 3 } \\
\text { Pretest } \\
\text { Postest }\end{array}$ & 69 & 10.343 & 19 & 2.093 \\
\hline
\end{tabular}

Note $\alpha=.05$

The results of analysis indicate that the mean scores of postest are greater than the mean scores of pretest in every group, i.e. $60>44,61>48,62>49$, and the results $t$-test analysis indicate that $t$-test $>t$-table in every group (group $17.424>2.093$, group $2 \quad 7.796>2.093$, group $310.343>2.093$ ). It means that the multimedia learning materials are significantly effective to use in teaching speaking skills.

\section{Conclusions}

The implementation of the multimedia learning materials in teaching speaking skills at university is practical and effective. The practicality of the multimedia learning materials is indicated by the leacturers' and the students' responses that are very good. Similarly, the effectiveness of the multimedia learning materials is also indicated by the significant difference between the pretest and posttest of the three groups.

\section{Acknowledgements}

This research received no specific grant from any funding agency in the public, commercial, or not-for-profit sectors.

\section{References}

Cunningsworth, A. (1995). Choosing Your Coursebook. Oxford: Heinemann.

Heaton,J. B. (1989). Writing English Language Test (New Edition). USA: Longman.

Ivers, K., \& Baron, A. (2010). Multimedia Project in Education. USA: ABC- CLIO.LLC.

Kanwar, A. S. (2007). Quality Assurance of Multimedia Learning Materials. Malaysia: Ministry of High Education.

Kellem, H. (2009). Principles for developing oral fluency in the classroom. JALT Journal, 33(1), 9-11. http://dx.dx.doi.org/10.1111/j.1540-4781.1986.tb05250.x 
Kemp, J. dan Dayton, D. (1985). Planning and producing instructional media. New York: Harper \& Row.

Long Beach Analytical Rubric. Retrieved from http://www.csulb.edu/divisions/ aa/personnel/ fcpd/resources/ge/ (July 10, 2012)

Mayer, R. E. (2001). Multimedia learning. Cambridge, UK: Cambridge University Press.

Neo, M. (2010). Students' Perceptions in Developing a Multimedia Project Within a Constructivist Learning Environment. TOJET: The Turkish Online Journal of Educational Technology - January 2010, volume 9 Issue 1.

Norhayati, A. M., \& Siew, P. H. (2004). Malaysian Perspective: Designing Interactive Multimedia Learning Environment for Moral Values Education. Journal of Educational Technology \& Society, 7(4), 143-152. 143 ISSN

Omaggio. (1986). Guidelaines for Oral Assessment. Retrieved from http://publicaciones. eafit.edu. co/index.php/cuadernosinvestigacion/article/viewFile/1320/1191

Plomp, T., \& Nieveen, N. (editors). (2010). An Introduction to educational design research. Netherlands: SLO.

Reeves. T. C. et.al. (2005). Design Research: A Socially Responsible Approach to Instructional Technology. Research in Higher Education. Journal of Computing in Higher Education, 16(2), 97-116. Key: citeulike: 4545197

Richard J. C. (1990). Developing Speaking Activities. From Theory to Practice. Retrieved from http://www.professorjackrichards.com/pdfs/developing-classroom-speaking

Sun Associates. (2002). Multimedia Projects. West Bolivar School District Summer Institute info@sun-associates.com

\section{Copyright Disclaimer}

Copyright reserved by the author(s).

This article is an open-access article distributed under the terms and conditions of the Creative Commons Attribution license (http://creativecommons.org/licenses/by/3.0/). 